\title{
The Problem-Oriented System of the Training Quality Management at a Higher Education Institution Based on Modern Management Tools
}

\author{
Mariya I. Abuzyarova \\ Associate Professor of the Department of Management, Doctor of Economics, Samara State University of Economics \\ Russian Federation, Samara, 141 Sovetskoy Armii Street, Samara, 443090, Russian Federation \\ Email: panda63d@mail.ru
}

\section{Doi:10.5901/mjss.2015.v6n5s4p11}

\begin{abstract}
In the present context, the quality of specialists training is an important characteristic, which defines the competitiveness of a higher education institution within the educational environment of a country and the competitiveness of a state within the system of geopolitical values. The ongoing education reforms take place in a country within the context of ever-increasing demands for the quality of university-educated specialists on the part of employers and the society in general. The quality of education in the modern world is of dual nature: it is simultaneously the purpose of the reforms conducted in the educational system of the countries, a means for self-fulfillment of the graduates from higher education institutions, and a measure of their compliance with the demands of the society in terms of professional competencies, moral culture, spiritual and physical health.
\end{abstract}

Keywords: education, competency, management tools.

\section{Introduction}

The current state of the society can be characterized by the increase in scale and pace of the social production growth and, as a consequence, by the unprecedented complication of socioeconomic processes.

Informatization of the society increases the intensity of information flows, causes the emergence of new knowledge, and changes the role of information in the economy, education, and culture.

At the same time, the system of education, which is focused on training bachelors and masters, is rather conservative (which can hardly be considered as a disadvantage), and has a clearly traced structure, interrelations, a system of requirements to the graduates from higher education institutions, etc.

In today's market economy environment, in which the number of private higher education institutions in the state exceeds the number of public education establishments, and the higher education is generally interpreted as a service; contradictions between the results of the education process (the quality of training) and the cost of education are inevitable. The desire to reduce the expenses for training bachelors/masters leads to the necessity of changing the methodological and organizational approaches to the process of specialists training. This is how the idea of the competency-based approach emerges (Zhukov, 2002).

\section{Methods}

\subsection{Implementation of the competency-based approach in higher education}

Competency is an integrated characteristic of the qualities of a person, has a procedural orientation and a motivational aspect, is based on knowledge, and manifests itself through the activity (real or modelled one) (Zhukov, 2002).

The dictionary of foreign words defines the term "competence" in the following two ways:

- As a range of issues, of which a person is well aware;

- To achieve, to correspond, to fit.

The same dictionary interprets "competency" as the possession of competence and knowledge that allow passing judgements on anything.

According to a number of scientists, competency means the specific ability of a person required to perform a particular action in a particular subject area, and containing the sector-specific knowledge; i.e., to be competent in a subject area means to possess a deep knowledge of the subject, to be able to set and solve tasks, to be capable of 
communicative interaction with colleagues, etc.

According to their definition, the competency-based approach is "a method for modelling and designing the results of education" (Zagrai, 2007).

From all of the above mentioned it follows that competences and their implementation for each particular person is a unique and sophisticated phenomenon. Therefore, within the concept of the competency-based approach, some researchers attach high importance to this approach positioning it as a foundation for the new educational paradigm.

The changes occurring in the society, the high level of information, and the transition to the new information technologies in almost all the fields of human activities impose new requirements to the system of higher professional education. Thus, it is quite natural that the research conducted in the field of the education system is aimed at finding an efficient way of education management in the present context.

That is why the idea of the competency-based approach to the training of bachelors/masters has been recently positioned as a very important and significant one due to the following several reasons:

- The changes occurring in the society require changes in approaches to the formation of a comprehensively developed person;

- For a successful professional activity, it is necessary to improve one's knowledge;

- The human role in the production undergoes certain changes: the structure of the organization should be based on the desires and abilities of a person;

The competency-based approach implements the idea of the new educational paradigm-the "anthropological paradigm": the importance lies not in the knowledge itself, but in its transformation into the activity.

According to some researchers (Zimniaia, 2008; Korneshchuk, 2007), the contemporary education can be characterized as a system that demonstrates a sufficiently high workload of students during the process of learning. At the same time, there is a trend to the "growth of insufficient knowledge," i.e. a discrepancy between the level of knowledge and the requirements of the labor market.

Indeed, a graduate from a higher education institution should possess a high level of knowledge and a creative personality focused on solving specific applied problems.

It is obvious that the professional and career growth of a graduate from a higher education institution depends not only on the basic education, but also on the desire to develop and renew one's competences.

The idea of changing the human role in the production process is of considerable importance in substantiating the significance of the competency-based approach.

Under the market conditions, a graduate from a higher education institution is not just simply a carrier of certain competences strengthened by the personality qualities, but also the main non-renewable resource of an enterprise, its primary asset that ensures competitiveness.

What is the way to implement the competency-based approach? What are its advantages and disadvantages?

An analysis of the cause-and-effect relationships within the system of "society-market - employer - higher education institution-graduate" shows that the competency-based approach roots to the new concepts of defining the goals and objectives of the education system.

The traditional system of specialists training at higher education institutions was focused on generating strong fundamental proficiency of a graduate, on developing his ability to self-education and enhancement of the professional skills, i.e. the mission of the higher education institutions was to establish the intellectual elite of the society.

The modern interpretation of education as a service changes the mission of higher educational institutions. Thus, higher education institutions are the suppliers of a certain resource to the labor market, and, accordingly, the requirements for the quality of the graduates training should be focused on the needs of employers.

Under such an approach to the mission, goals, and objectives of the higher education system, it is proposed to accept the following interpretation of terms:

- Competences are the subjects and types of activity of a graduate;

- Competency is what a student has learnt and mastered during the period of training, i.e. competency is interpreted as a measure of mastering competences;

- Competency-based learning is an educational environment that includes several educational modules intended for the development of a certain competency within the professional activity.

Such an interpretation positions the competency-based learning as the major means for providing interaction within the system "higher education institution - employer" as well as between higher education institutions within the uniform educational environment.

Wherein, the dynamic nature of the labor market requirements and the change of the priorities and preferences 
within the system of market relations should motivate higher education institutions to the constant monitoring of these requirements and adjustment of appropriate education programs in order to develop the currently relevant competences.

No doubt that there is a need not only for a special technology of assessing market requirements and for the adaptation of higher education programs to these requirements, but also for the community of professionals, who can assess the significance of the problem of training, retraining, and advanced training of specialists in a certain subject area, as well as the development of corresponding teaching technologies.

Since 1999, higher education institutions started to introduce on a trial basis a credit-based teaching technology. Such a transition was caused by the necessity of establishing a system of the comparative and comparable qualification profiles of university-educated specialists by using the accumulative and conversable credit system (Nuzhdin and Kadamtsev, 2003).

The key concept of the Bologna process is the learning outcome (LO), which has been selected as the primary element of the contemporary system of higher education.

According to the philosophy of the Bologna process, the development of learning outcomes should focus on the student, his system of preferences and wishes in acquiring knowledge and qualification.

The learning outcomes should be formed in accordance with the levels of hierarchy:

- Level 1 - the level of a higher education institution: teaching by appropriate programs and technologies;

- Level 2 - the guarantee of education quality and professional competency;

- Level 3 (international) - ensuring the transparency and the ability to compare the learning outcomes.

LO were selected as the basis for the classification of competences (Nuzhdin and Kadamtsev, 2003).

Competences are classified according to the nature of their manifestation in the LO:

- General competences, which will allow a specialist to carry out an analysis and synthesis of the task in hand, to conduct discussions in abstract terms, to easily adapt to the activity conditions, etc.;

- Subject-related competences, which reflect the skills and abilities to solve specific problems of a subject area in an organized and systematized manner, etc.;

- Academic competences, which are the ability to think systemically, to establish interconnections, the causeand-effect relationships, etc.;

- Social competences, which are associated with the personality qualities, and the willingness to live in the conditions of globalization.

No doubt that any classification is relative, and this one is of no exception. Moreover, the attempt to break up competences into individual groups (classes) prevents from the adequate assessment of the prospects for development of a certain competence, its reflection in the learning outcomes.

In order to implement the competency-based approach, it is proposed to refuse from the commonly accepted terminology ("knowledge - abilities - skills") and learn to present the education opportunities in the terms of LO.

At the same time, the LO may be subject to the decomposition and detailing. Accordingly, the educational trajectories focused on such LO should be formed under the modular principle.

This minimizing nature of the competency-based approach makes it possible to:

- Define the expected learning outcomes;

- Reduce the costs required for training a bachelor/master;

- Build a minimized model of a bachelor/master;

- Define the prospects for the development of the built models of bachelors/masters.

Regarding the classical system of education, which was built under the "Sit \& Listen" principle, it should be noted that the main purpose of the higher professional education was the formation of knowledge. The applied aspects involving the application of knowledge in practice were of secondary importance.

The adaptation of the acquired knowledge to the real production and life situations was not usually provided in the teaching of academic disciplines.

Acquisition of the skills of applying the theory to practice within the system of higher education was provided within the framework of the production and professional practical works. The changes occurring in the world, in the society, and therefore, in the state led to the necessity of changing the concept of education: the "Sit \& Listen" at higher education institutions was gradually replaced with the "Think \& Do" technology.

Thus, the active methods of learning appeared in the practice of teaching.

According to the definition by Rybal'skii (Frolov and Makhotin, 2004), active methods of learning are a set of methods for organizing the teaching and learning activities, which, compared to the traditional methods, feature the following basic characteristics: 
- The forced intensification of student's thinking during the classes;

- The independent development of the solutions;

- The constant interaction between a teacher and a student through feedbacks.

The author also classifies herein the methods of active learning into two groups:

- The non-simulating methods (lectures, seminars, workshops);

- The simulating methods comprising business games, case studies, simulation exercises, and game-oriented designing.

Over time, the simulation methods have become widely spread and deserved due international recognition.

In 1992, the International Simulation and Gaming Association (ISAGA), the session of which took place in Saint Petersburg, upon an initiative of the professor Zhukov accepted the "game-based social simulation modelling" term for denoting the active methods of simulation.

It was also suggested therein to break up the methods of game-based social simulation modelling (GSSM) depending on the method's purpose and structure into the following groups:

- Simulation exercise;

- Analysis of specific situations;

- Business game;

- Game based on the organizational activity;

- Game designing;

- Method of active sociological testing, analysis, and control.

Regarding the effectiveness of introducing the GSSM as a new information technology into the educational process practice, it is necessary to assess adequately the contemporary requirements for the level of training among graduates from higher education institutions. It is obvious that a great volume of knowledge is not the limit for the successful professional activity.

The individual sources provide the classification of knowledge by the levels of hierarchy, which suggests that the knowledge should be divided into the theoretical and introductory one, wherein the theoretical knowledge plays the role of foundation, on which the practical knowledge is based. While the major role is assigned to the so-called introductory knowledge, which is based on the experience gained through observing the activity.

The competency-based approach suggests that the introductory knowledge should prevail, and during the process of training, the activity modelling should be preferred, since it is the modelling that allows converting theoretical knowledge into practical skills.

Such an approach to the educational process of higher education is seen as not quite consistent with the contemporary requirements to the higher professional education.

The ideology of the innovative technologies based on the game-based social simulation modelling at a first glance appears to share common features with the competency-based approach:

- Arranging a dialogue during the process of training;

- Focusing the training on the study of processes;

- Enhancing the motivation to learning.

At the same time, there is a fundamental distinction, which consists in that the competency-based approach is of minimizing nature, and the GSSM provides the possibility of establishing the integrated characteristics of the trainee's personality, which allow him to achieve a high professional status.

This conclusion is based on the analysis of the effectiveness of two different methodological approaches to education.

The first scheme-"Sit \& Listen"-involves passive learning corresponding to the traditional system of education.

The second scheme-"Think \& Do"-is based on the new technologies that contribute to the active analysis of the theoretical material, and to the formation of the new synthesized knowledge, which combines the theory, the results of the practical activity of a trainee, the information from the related subjects, etc.

The fact that the GSSM methodology allows exceeding the scope of the "knowledge, abilities, skills" format when training bachelors/masters is of particular significance. This can be explained by the fact that the activity teaching is of an invariant nature, while the trainees' focus on mastering the methodology of acquiring knowledge and forming the experience of its application in practice can be implemented in any other activity.

A number of authors argue that the analysis of the competency-based approach's impact on the results of the training process reveals certain advantages over the classic and traditional educational paradigm.

At the same time, it is necessary to assess objectively the problems arising in connection with the introduction of 
innovations into the practice of higher education, as besides the advantages, serious challenges are also revealed:

- Absence of systematicity in the methodology of the competency-based approach;

- Absence of the technique for assessing the competence formation;

- A consumer (student) is offered a service (educational paths), the purpose of which (the learning outcome) has not been realized by the consumer;

- It appears to be impossible to use quantitative assessments for each student when arranging the team work on the formation of competency;

- The modelling of the activity of a future bachelor/master during the process of competences formation is usually of simplified and approximate nature; an approximation error can minimize the learning outcome;

- There is no system for assessing the quality of both the process of learning itself and its outcomes.

\section{Results}

\subsection{The process approach to the education quality management at a higher education institution}

The State Concept of Higher Education of the Russian Federation, which incorporates the ideas of the lifelong learning and comprehensive development of a person, requires rethinking not only the methodological bases of the system of training higher education professionals, but also the mission of higher education institutions.

The education quality management is primary the system of thinking, then the methodology, and then the technology, i.e. standards, means, and methods for assessing the quality and managing the quality (Okrepilov, 2003).

Currently, the system of higher professional education of the Russian Federation provides an opportunity to study at state and private higher education institutions.

The system of government grants within the education system introduced by the Russian Federation is established on a conceptual level in accordance with certain principles:

- The government order is generated based on the analysis of the demand of enterprises and organizations for bachelors/masters;

- The government order is allocated between higher education institutions taking into account the desires of the applicants and the rating of a higher education institution;

- Government grants are provided to those applicants, who have achieved excellent results in passing the Unified State Exam.

The opportunity of obtaining higher education on a paid basis, that is, with the full cost recovery, fundamentally changes the goal setting of a higher education institution and of an applicant.

On the one hand, the government benefits from the development of the private sector within the system of higher education, since it allows activating all the related industries, creates a competitive basis in the operation of higher education institutions, provides an applicant with the opportunity of free self-determination when choosing a higher education institution.

The commercialization of higher professional education has led to a number of problems:

- Higher education institutions transform from the establishments of education into commercial structures, that is, the concept and method for managing the educational process are completely changed;

- Higher education becomes available for the school graduates with low level of knowledge;

- The number of students with the high Unified State Exam score is much lower than the number of students who did not receive grants and were enrolled to a higher education institution for studying on a full cost recovery basis. Therefore, the principle of competitive selection is violated during the formation of the student contingent;

- It is rather difficult to fulfill the higher education institution's programs in classrooms filled with the students featuring poor knowledge of the school program;

- All the above leads to the devaluation of higher education.

During the entire period of reforming the system of higher education, certain measures were taken for optimizing the activity of higher education institutions.

Currently, while defining a higher education institution as a part of the system, which combines the intellectual potential of the state, the information resources, the material and technical basis, and in accordance with the national system for assessing the quality of education, the following strategical goals have been determined:

- Implementing the state policy in the field of higher professional and postgraduate education; 
- Establishing a high level of culture (informational, technical, political) of graduates from higher education institutions and of the society in general;

- Defining the mission of higher education institutions;

- Improving the entire system of higher education;

- Introducing advanced technologies for training competitive bachelors/masters.

Such an approach will ensure the following advantages:

- A high level of specialists training;

- The use of the standardized assessment system and units of measurement (credits);

- Compliance with international standards of education;

- Training in accordance with integrated curriculums;

- The possibility of joining the international educational space.

Defining the goals is the first stage in solving the problem that provides for the formal description of a problematic situation, the desired result, and the objectives, and specifies the initial data on the resources.

The next stage should define the means and methods for achieving the set goals.

A number of scientists propose to consider the process-based approach as one of the new approaches to solving the problem of quality management.

With this definition of the process, such concepts as "process", "consequence of actions", "technology," and "process-based approach" have been distinguished.

Thus, a process is a structured, purposeful set of interrelated types of activity, which according to a specific technology converts the inputs and resources into the outputs (products) being of particular value for the consumer.

The "process-based approach" term implies the idea of managing the quality of the finished products through managing the process of their production.

The modern research of the implementation of the process-based approach into the practice of management characterizes this approach as a unique quality management tool.

The large number of publications on this issue makes it necessary to define the criteria of assessing the effectiveness of the implementation of the process-based approach:

- Clear identification of processes, their inputs, outputs, and limits;

- A system for assessing the results of each process and its impact on the general result;

- A system of interaction between the processes and owners;

- All employees clearly understand the process, in which they are involved, and their role in achieving a common goal;

- There is a mechanism for continuous enhancement of the efficiency of processes.

The process-based approach changes the essence of management.

In order to move to the process-based management, two strategies are proposed:

- The management within the traditional structure;

- The management instead of the traditional structure.

The so-called "soft" implementation of the process-based approach involves preserving the traditional organizational structure. However, the composed clear description of the processes should be associated with the corresponding structural subdivisions performing their functional duties.

According to the terminology of the process-based approach, the head of a subdivision becomes the owner of the process, but at the same time, he (the head) is the resource owner. The structure availability provides for clear limits of the process and the interaction therebetween.

This technology features certain advantages:

- The principles of the process-based approach are observed;

- There is no need in sweeping changes in the enterprise structure.

At the same time, such an integral combination of various approaches to management features certain drawbacks:

- The viability of such a hybrid is doubtful;

- The structural subdivisions established on a functional basis may not coincide with the processes;

- Reorganization is required in order to establish the correspondence of the structural subdivisions and processes.

Thus, during the implementation of the process-based approach, the reorganization of the structure is inevitable.

The implementation of the process-based approach according to the principle of the complete change in the 
structure of an enterprise is based on the assertion that the classic hierarchical structure has a number of significant drawbacks, which are incompatible with the process-based approach.

Such drawbacks include:

- Division of functions in a hierarchical manner;

- The head of the subdivision is the consumer of the labor outcomes;

- Circularity of the structure (functional barriers);

- A shift of priorities: the processes are ranked not according to their value, but according to their cost;

- Excessive information flows;

- Total control as a method of quality management.

The system of management, which is focused on the process-based approach, requires the following changes in the structure of the management system, in the methodology and style:

- The changes in the structure will require a transition from the hierarchical structure to the process-oriented one;

- The changes in the methodology of management should generate a team style of working, in which the priority will be given to the participation in the process combining several functions instead of the activity division by functions;

- The changes in style will require positioning the heads of subdivisions as the process owners, and therefore, changing their goals and objectives.

At the present stage, the goals of higher education institutions are of a multifaceted nature:

- Training of specialists in accordance with the classifier of the Russian Federation and the State Compulsory Education Standard;

- An increase in the level of specialist training;

- An increase in the profitability of higher education institutions.

It is obvious that at those information flows, which the head of a higher education institution is required to analyze for achieving the goals, it is necessary to change the technology and methodology of management, and switch from the heuristic and intuitive methods to the scientific ones.

The contemporary status of the system of higher education, which is a complex dynamic system and can be referred to the class of professional systems, also requires new approaches to the process of management.

At the first stage, the implementation of the process-based approach requires the self-determination of higher education institutions in terms of their goals, position, and situation. Such self-determination in itself is quite a complicated process.

The conducted studies allowed us to determine that in relation to the system of higher education, the processbased approach and the transition to the management of processes mean the following:

- Defining the mission of a higher education institution;

- Defining the goals and objectives of a higher education institution;

- Defining the processes and determining their compliance with the goals and objectives of a higher education institution;

- Determining the system of interrelation and interaction between the processes;

- Identifying the characteristics of a process: its owners, inputs and outputs (results), methods for assessing the efficiency of the processes;

- Composing the description of each process and establishing appropriate regulation;

- Introducing the corresponding documentation to the faculty and other staff of a higher education institution; conducting the training and methodological seminars on the process-based approach;

- Managing the processes;

- Developing a mechanism for the continuous improvement of processes with regard to the motivational component.

The implementation of the process-based approach within the system of higher education is possible in two different ways:

- Within the framework of the traditional structure;

- Instead of the traditional structure.

We have found out that regardless of the chosen strategy of behavior, the main difficulties of a higher education institution during the implementation of the process-based approach start at the stage of defining the process and its 
owner, and at the stage of determining the compliance of the process results with the goals and objectives of a higher education institution, and its mission.

Let us define the mission of a higher education institution as of a system intended for training specialists of a specific profession, who possess a high level of qualification, are capable of self-fulfillment in the labor market, and meet the requirements of the society. Such a definition of the mission of a higher education institution makes it possible to formulate the goal and objectives of a higher education institution ("A Decade of Reforms at Compulsory Education," 1997; Van Haecht, 1993).

The goal of a higher education institution is to improve the quality of specialists training.

The objective of a higher education institution is to develop and implement adequate techniques for assessing the quality of training, for managing the quality in accordance with the problems arising within the system of education.

Let us define the following process in accordance with the above-mentioned goal and objective:

- The supporting processes: the learning process, planning of the activity of faculties, chairs, and individual teachers, establishment of the material and informational assets; maintenance of the equipment, etc.;

- The main processes: entrance exams, enrollment of students, establishment of the faculty, development of the curriculum and academic documentation, and the training process itself;

- The processes of management: strategic planning for the higher education institution development, marketing research aimed at revealing new majors, search for the bases of practices and assistance in employment, finance and quality management.

Despite the common goals and objectives of the system of training specialists, the processes of training on socialhumanitarian, pedagogical, and technical specialties feature significant distinctions. Therefore, in accordance with the principals of the process-based approach, the description of these processes should be carried out separately.

Moreover, when assigning the owner of the "learning process," we face the necessity of dividing this process into the following stages: the organization of the learning process and the implementation of the learning process, since the learning process is usually organized by the curriculum and instruction department, and implemented by the appropriate department.

Further, regardless of the course and form of training, a student simultaneously studies several (7 to 10) subjects during a semester, wherein the curriculums of the same course of various forms of training differ in the number of academic hours, the hours intended for the independent work, etc.

Consequently, the descriptions of these processes will feature significant distinctions; each of them should be presented as an independent process with its own inputs and outputs, owners and resources.

Each process, activity, or objective is initiated and performed as and when required, wherein there are no predetermined sequences, however, the logics of links should be preserved according to the initial information and objectives.

The complexity of implementing the process-based scheme of quality management within the system of bachelors/masters training lies in the need to control both the resources and processes simultaneously.

From the process-based approach perspective, it is proposed to consider in general the process of bachelors/masters training without distinguishing individual structural subdivisions and their functions.

Such positioning of the quality management system inside a higher education institution allows considering the faculty as the major resource, the quality of which directly affects the outcome of the process.

It is obvious that a teacher as a part of the professional organization is a carrier of the professional competencies. At the same time, the teacher directly affects the process of forming both the bachelors/masters as the professionals in a specific subject area and a personality with the relevant ethical, moral, and civic positions.

This is why the faculty of a higher education institution involved into the training process is not only regulated by the administration of a higher education institution in the person of the department chairman, dean, etc., but no less bears responsibility in accordance with the rules of the professional ethics in front of its colleagues.

From the perspective of the process-based approach to the quality management, this means the equivalence of certain structure elements, the equal responsibility for the labor quality and results at each stage of the training process.

Thus, from the perspective of the process-based approach, the education quality management is reduced to managing the quality of individual processes. In a higher education institution, the individual processes mean the teaching of individual subjects or blocks of related subjects as well as the processes of educational and scientific work.

A teacher passing the outcome of his work to a colleague is the supplier teacher; a teacher accepting this outcome is the consumer teacher. This dual function of a teacher (simultaneously the consumer and the supplier) is the main difficulty of implementing the process-based management of the education quality, since it requires: 
- Generating a network structure, which establishes a clear allocation of roles (a supplier, a consumer, an owner of the process) in relation to all the subjects of the curriculum;

- Having clear requirements for the quality of outcomes of each process;

- Developing the forms of the formative and summative assessment of knowledge on each subject;

- Providing feedback between the structure's elements;

- Developing a system of managing and adjusting actions, and their performing through the system of quality management.

The implementation of the process-based approach to the quality management requires combining the processes into groups according to the terms, resources, etc.; managing the quality of outcomes through the process quality management; grouping the processes.

The implementation of the process-based approach can be presented as an algorithm (Figure 1).

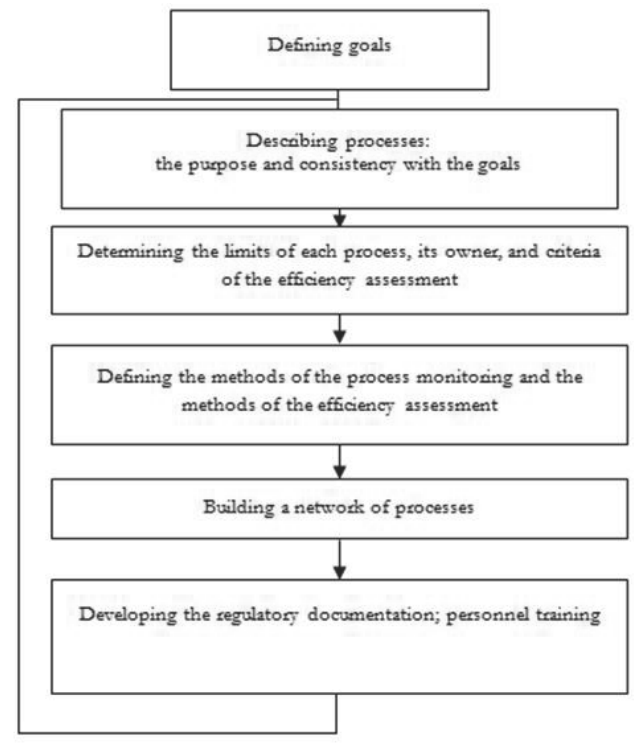

Figure 1. The algorithm of the process-based approach implementation

In adapting the ideas of the process-based approach to the system of higher professional education, the listed features become the additional obstacles to the successful reorganization of the professional structure into the process-oriented one.

This sequence ensures the compliance with the principles of the process-based management and the transition from the functional-hierarchical structure to the process-oriented one.

With such an approach, the system of quality management will possess the following view (Fig. 2). 


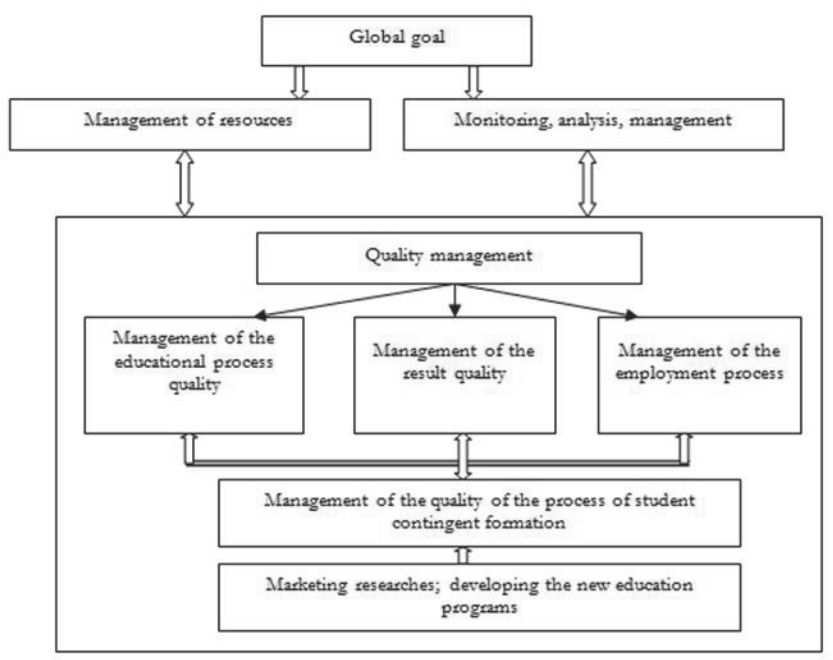

Figure 2. The structure of the quality management system in the process approach

Thus:

- The application of the process-based approach to the system of education in general and as a management tool for training bachelors/masters is rather problematic;

- The management of the commercial production and the system of education should be based on different conceptual foundations;

- The systematic approach to the development of a problem-oriented system of the education quality management is required.

\subsection{The methods for evaluating the quality of training of the graduates from the higher education institutions}

There are two points of view concerning education and its quality management system:

- The compliance with the tight standards and the method for transmitting knowledge, abilities, and skills from one generation to another. In this approach to the educational process, the quality management consists in controlling the standards and rules of the process of education, determining the degree of compliance of the acquired knowledge, abilities, and skills with the established level. It is obvious that in this case, the availability of the system of standards as well as the authorized bodies for monitoring these standards is required. The national standard provides no guarantees that the experience, skills, knowledge, and abilities of the previous generations will be mastered by the trainees during the process of transmission. In this approach, the assessment of the final result's quality is defined as the ratio of the number of students who do not have the "satisfactory" mark to the total number of students.

- The task of producing a bachelor/master according to the alternative principles is considered primary.

In our opinion, it is obvious that the training of bachelors/masters for each level should be conducted according to its own algorithm.

From this perspective, a system-based approach to learning involves the formation of a new model of training, which gives the opportunity of not only acquiring the professional knowledge and skills, but also of realizing oneself and one's own position within the framework of the new public, social, and economic system.

The problem of the education quality management in Russia remains urgent.

The essence of this problem lies in the difference between the approaches to education and its objectives.

The higher education institutions of the Russian Federation operate under the conditions, which can be characterized as follows:

- The shortage of specialists/bachelors/masters of technical majors, and the overproduction of specialists/bachelors of the law and economic profiles; 
- The strengthening of the requirements to the quality of training on the part of consumers of educational services (students, parents, enterprises, and organizations);

- The absence of state distribution of graduates from higher education institutions.

Thus, the management of the training quality should be considered as the quality management for the process of training as such. It is obvious that for the provision of the optimal quality of the specialists training, higher education institutions require the consistency in the quality management.

The contemporary system of personnel training is characterized by the high level of implementation of information technology with the simultaneous strengthening of the requirements for the person's quick adaptation to the changing conditions of life.

This is the reason for the contradiction between the system of the educational process rationing, its standardization, and requirements for the mobility of bachelors/masters and their willingness to perceive and apply innovations in their professional activities.

It is possible to eliminate this contradiction through the introduction into the system of higher professional education of the credit technology, which allows us to solve the following three tasks:

- Opening the access for students and teachers to the world educational space.

- Developing competitively attractive education programs in higher education institutions of the Russian federation.

- Implementing the system-based approach to the management of the bachelors/masters training quality.

The monitoring of the quality of knowledge acquired by a student plays an important role in implementing the system-based approach to the quality management.

The works on the quality of education propose to consider the quality of bachelors/masters training through the system of indicators ("Method for Improving the Quality of Higher Education", 1999; Van Haecht, 1994).

An indicator is a generalized and enlarged characteristic of an education program of a higher education institution.

Each indicator corresponds to a certain system of indicators that reflect the content and the form of the education program and/or its elements.

The methodology for applying the system of indicators features a number of advantages:

- It allows implementing the principle of systematicity;

- It considers the interests of all participants of the education process;

- It allows assessing the focus of the education programs.

As a result of the conducted studies, the concept of the training quality management through the strategic and operational management was developed.

The main goal of management is the monitoring of parameters of an education institution.

Two methods of quality management are proposed based on the international standards:

- To restructure the education institution (EI) and complement the traditional structures with the elements that ensure the sustainable, competitive advantages in the market of educational services. This method will provide the El with certain advantages in the tactical and image-building aspects, but will hardly enable the significant improvement of the quality of education.

- The system-based reorganization of the educational activity management is required, which is capable of providing a radical change in the goals, structure, and functions of the El.

The studies are aimed at identifying various approaches to assessing the quality of education. It is proposed to introduce the unified information indicators of accreditation of the professional education programs.

In consideration of the quality of education as the priority direction in the activity of a higher education institution, it is suggested to pay special attention to the cooperation of higher education institutions with schools.

The results summation allowed us to establish a unified approach to the system of education quality assessment.

The indicators on each of the criteria are divided into two groups:

- The results of self-examination;

- The results of independent experts.

Such structuring of the results confirms the necessity of a systematic approach to the quality management.

Summing up the results of the analysis in the field of education quality management, we need to note that:

- The models of quality management proposed by foreign and domestic experts usually define the requirements in terms of learning outcomes, whereas it is necessary to assess the quality of the process of bachelors/masters training;

- There is no mobile system for exchanging the information resources on the issues of quality management, 
which is based on the achievements of the domestic and foreign scientists, researchers, and practitioners;

- It is required to develop such a system of interaction between the participants of the educational process and the parties concerned, which will allow concentrating the positive experience in the education of competitive bachelors/masters.

The activization of higher education institutions in the international educational and scientific cooperation, which has been outlined during the last decade, blurs the line between the local and the global, the national and the international, and allows us not only to borrow the foreign methods of training, but also to coordinate the policy of quality assessment on the institutional, national, and international levels.

A significant place in the system of criteria for the education quality assessment is devoted to such indicators as the quantity of employed graduates and the quantity of graduates enrolled to the programs of the postgraduate training.

The number of graduates employed according to their specialty (especially in prestige professions) allows us to determine the degree of demand for the graduates of a given higher education institution.

This is the indicator that is the main one for assessing the rating of a higher education institution among higher education institutions of the Russian Federation and the efficiency of the educational process in a certain higher education institution. Continuous communication of a higher education institution with its graduates and an analysis of the employers' reviews on the quality of bachelors/masters training provide additional information that enables adjustment of the training technique.

The introduction of a two-stage system of personnel training in the Russian Federation involves acquiring by the students of the bachelor degree with the right to continue education in the master training programs.

The establishment of the extensive international relations of the Russian Federation in the field of education and scientific personnel training expands opportunities of the students, since a number of higher education institutions have cooperation agreements with the higher education institutions of the far and near abroad.

The conducted studies made it possible to establish that the employers, taxpayers, and trainees applied different criteria to the assessment of quality.

If we agree that the quality of bachelors/masters training is the characteristic that completely defines the requirements of consumers, i.e., if the level of training of a graduate from a higher education institution meets the claims of the employer, the education can be considered of high quality. It is obvious that the quality assessment becomes subjective.

With this approach to the quality assessment, the concepts of the standard and compliance with the standard lose their meanings since the quality transforms from the objective indicator into the subjective assessment, which fully depends on the system of preferences and the level of expert qualification.

Moreover, the positioning of education as a service requires considering the educational process as a technological process of producing a certain type of product-highly qualified professionals.

In order to establish a unified system of criteria for the quality assessment, we propose to interpret the term of "quality" in the descriptive aspect as a degree of conformance of the educational process and its outcomes with a certain standard (reference sample).

The assumption can be accepted provided the standard is defined and the category of "quality" is decomposed into individual components due to its complexity and the ambiguity of its hierarchical structure. The purpose of this decomposition is to determine the links between the components and to analyze their impact on the results of the education process.

The decomposition of the quality of bachelors/masters training shown in Figure 3 defines the basic components that affect the overall result. 


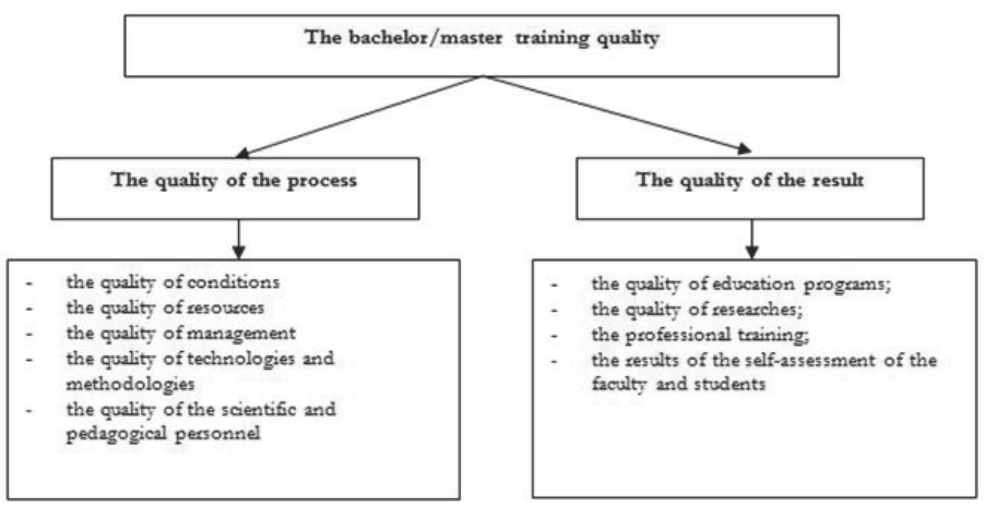

Figure 3. The decomposition of the bachelor/master training quality

The division of quality into two components - the quality of process and the quality of result - provides for the development of models and algorithms, which define the problematic moments during the process of bachelors/masters training, and thus, for the timely development of the control actions.

At the same time, a trained specialist in addition to all his professional skills is assessed by the society according to alternative criteria.

Figure 4 shows the education quality decomposition. It is obvious that such decomposition is necessary for defining the system of requirements imposed by the society on highly qualified bachelors/masters. The criteria for assessing the professional training are integrated together with the criteria for assessing a person as an object of the professional activity of the faculty of a higher education institution.

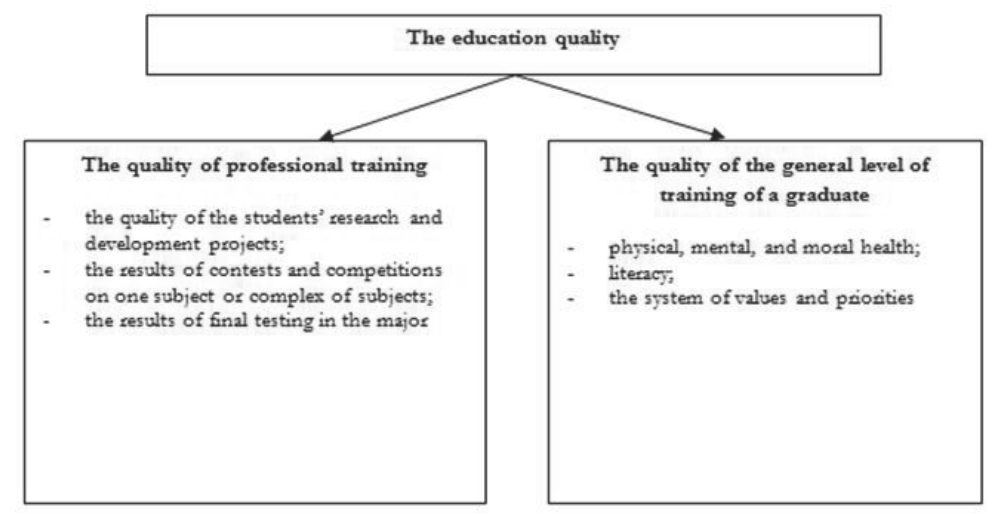

Figure 4. The quality of education decomposition

The constructive aspect of the education quality in terms of the functional-cybernetic approach requires the development of a system of measurement and quality assessment as well as a monitoring system.

Currently, the education quality assessment is carried out in several directions:

- The international level (accreditation);

- The state level (independent expert evaluation, certifications, and accreditations);

- The internal system of quality management within a higher education institution;

- The assessment of consumers: the employers (rating of higher education institutions and their graduates), and the students.

Despite the fact that the assessment techniques differ on each level, the systematic approach to the assessment 
makes it possible to use a unified methodological framework when choosing or developing methods.

When developing a system of measurement and quality assessment, it is required to define the means and methods of quality measurement, and to develop the criteria of quality assessment (who and how assesses?).

The constructive aspect of the education quality considers the ways of quantitative assessment of the education quality.

Thus, taking the criteria-based assessment of the quality of bachelors/masters training as a basis, first of all, it is necessary to define the object of study; then one can proceed with establishing the system of criteria for assessing the quality of a given object.

Considering education not only as a process of transferring knowledge, abilities, and skills, but also as a process of forming a professional, we will choose the following characteristics as the criteria-based assessment:

- Compliance with the standards of the educational process as such: the quality of the faculty who participate in the process of education; the quality of applicants and students: their ability to self-development, professional activity, and learning; the quality of training techniques (the contemporary methodologies);

- Compliance with the standards of the learning outcomes: the integral criterion of the quality of professional training;

- Compliance of the outcome with the requirements of a trainee: the trainee's ability to work, the provision of the opportunities for career growth, the provision of the adequate standards of living, etc.;

- Compliance with the requirements of the society: the level of the specialist's general culture, his moral and physical health, etc.;

- Compliance with the requirements of the employer: the ability to fulfill the set tasks on the appropriate professional level.

The regulatory aspect is the creation of a regulatory base for assessing the quality of specialists training and the quality improvement techniques. The regulatory aspect of quality involves the formation of a standard (reference sample) of the education quality as well as the development of such techniques for implementing the educational process that will allow executing this standard.

This system covers all the components and directions of the activity of a higher education institution, and also involves the availability of feedback of the graduates and employers.

The information aspect of quality consists in the fact that when assessing the educational activity of a higher education institution, an education institution is considered as a complex dynamic system, in which the activity outcomes are significantly influenced by the internal information flows and by the information coming from the external environment.

The information aspect allows us to define the structural and functional components of the educational process, the direction of the information flows, and their interaction both inside the system and in the interrelations with the external environment.

The following several information flows are distinguished within the education process:

- The teacher-to-student transfer of information;

- Conversion of the information by the student, i.e. the formation of knowledge, abilities, and skills;

- The student-to-teacher transfer of information;

- Processing of information and adequate assessment of knowledge.

Besides, there are information flows coming from the external environment, which according to their nature are divided into the generally methodological and the technical-technological ones.

The first group includes the information on the standards and rules of the quality assessment that are valid within the country and abroad, the data on the integrated assessments of higher education institutions, etc.

The process of quality management based on the new information technologies starts from building the information model of a subject field, and from determining the intensity of the information flows from the system of management to the object of management.

The requirements imposed on the information model are obviousness; visibility; unambiguous comprehensibility by the developers and users.

The information model should include:

- A system for coordinating and classifying the components of the object of management, developed and unified forms of document management;

- Algorithms for collecting, processing, transferring, storing, and reproducing the data.

The timely performed assessment of the intensity of information flows, the determination of the purity of data collection, and the forms of their presentation to the decision-making person will enhance the efficiency of the quality 
management system.

The issue of assessment of the activity quality has caused the emergence of a variety of different assessment systems.

Numerous studies dealing with the issue of quality of the bachelors/masters training describe the formation of the basic concept of solving this problem as the focus on the system of consumer preferences.

The innovative aspect of this problem consists in the fact that when the adequate assessment mechanisms are developed, it is required to apply the known methodological and theoretical approaches for solving new problems.

Thus, the use of the methods of gaming social simulation modeling in the education process improves the quality of the bachelor/master training within the framework of the academic and postgraduate education programs, i.e., there is a dependence of the quality of training on the targets and on the methodology of the education process.

A scheme of the management process assumes the availability of the following components:

- The reference sample, to which the system under study should tend;

- The calculated path of the system movement;

- Means that allow assessing the actual state of the system and comparing it to the reference sample;

- A mechanism of influencing the system in order to bring it to the reference sample's level.

With this approach to the quality management, it is required, given the specificity of the education process, to determine the reference sample and the tools, which will help to determine the actual state of the level of training of each individual student and of the system of education as a whole, as well as the mechanism for comparing the actual level to the reference sample.

\section{Conclusion}

An analysis of the main trends of the modern education makes it possible to identify the challenges of the process of bachelors/masters training in the XXI century:

- The contemporary production, technologies, and the surrounding world in general are being dynamically changed. In this regard, we observe the growing role of lifelong learning, which is a universal way to adapt a person to the changing external conditions.

- The development of the information and communication technology can improve the mobility of educational activities and ensure the use of educational resources under the conditions convenient for the trainee.

- The implementation of the information technology in all spheres of activity along with the necessity for adapting persons and organizations to the changing conditions of life calls into question the appropriateness of tight regulation and standardization of the education process.

- The classification of the types of activity by specialties reflected in the rarely updated classifiers of higher education and professional education is also inadequate to the real practice of the industrial activity of the graduates from higher education institutions.

- The education process is not ended as the diploma of higher education is given-we observe the increasing role of postgraduate education as a means of inclusion in the process of the lifelong learning and adaptation.

- Commercialization of education and the availability of a competitive market of education.

- Interpretation of the educational process as a service, and the substantiated thereby enhancement of the requirements to the quality of educational process on the part of the consumers (students, employers, etc.)

- The need to establish and develop the demand for self-education and improvement.

- The influence of the quality of education on the development of science, innovative technologies, and the strategic development of the country.

- The emergence of a new mission of education based on the information technology: education as a means of improving the quality of life for disabled people.

\section{References}

A Decade of Reforms at Compulsory Education Level in the European Union (1984-94) (pp. 31). (1997). Brussels.

Frolov, lu.V., \& Makhotin, D.A. (2004). Kompetentnostnaia model' kak osnova otsenki kachestva podgotovki spetsialistov [A Competence-Based Model as a Basis for Evaluating the Quality of Specialists Training]. Vysshee obrazovanie segodnia - Higher Education Today, 4, 34-37 [in Russian].

Korneshchuk, N.G. (2007). Obrazovatel'naia kvalimetriia kak sistemnyi instrument kompleksnoi otsenki kachestva deiatel'nosti obshcheobrazovatel'nogo uchrezhdeniia [The Educational Qualimetry as a Systemic Tool for Comprehensive Assessment of the 
Activity Quality of a General Education Institution], monograph (pp. 97). Magnitogorsk: MaGU [in Russian].

Method for Improving the Quality of Higher Education based on the EFQM Model (pp. 88) (1999). Eindhoven: Expert Group.

Nuzhdin, V.N., \& Kadamtsev, G.G. (2003). Strategicheskoe upravlenie kachestvom obrazovaniia [Strategic Management of the Education Quality]. Vysshee obrazovanie segodnia - Higher Education Today, 4, 6-13 [in Russian].

Okrepilov, V.V. (2003). Menedzhment kachestva [Quality Management] (pp. 992). Saint Petersburg: Nauka.

Van Haecht, A. (1993). Partage des responsabilites aux niveaux national, regional et local dans des systemes educatifs de vingt-trois pays europeens (pp. 16-17). Strasbourg.

Van Haecht, A. (1994). Sharing of Responsibilities and Powers between Local, Regional, and National Authorities in the Field of Education (pp. 8-9). Strasbourg.

Zagrai, N.P. et al. (2007). Kriterii i pokazateli kachestva obrazovaniia [The Criteria and Indicators of the Education Quality]. Vysshee obrazovanie v Rossii - The Higher Education in Russia, 4, 35-42 [in Russian].

Zhukov, R.F. (2002). Ob akmeologicheskoi modeli spetsialista, sootvetstvuiushchei trebovaniiam rynka truda modeli spetsialista [On the Acmeological Model of a Specialist Meeting the Requirements of the Labor Market of the Specialist Model]. In the Collection of Proceedings: Aktivnye metody obucheniia - Active Methods of Training (pp. 103-107). Saint Petersburg [in Russian].

Zimniaia, I.A. (2008). Kliuchevye kompetentsii kak rezul'tativno-tselevaia osnova kompetentnostnogo podkhoda v obrazovanii [The Core Competencies as an Effective-Target Basis for the Competency-Based Approach in Education] (pp. 146). Moscow: Narodnoe obrazovanie [in Russian]. 